\title{
End-of-life practices: The opinions of undergraduate medical students at a South African university
} \author{
G Joubert, ${ }^{2}$ BA, MSc; W J Steinberg, ${ }^{3}$ MB BCh, DTM and H, DPH, Dipl Obst (SA), MFamMed, FCFP (SA) \\ ${ }^{1}$ School of Medicine, Faculty of Health Sciences, University of the Free State, Bloemfontein, South Africa \\ ${ }^{2}$ Department of Biostatistics, Faculty of Health Sciences, University of the Free State, Bloemfontein, South Africa \\ ${ }^{3}$ Department of Family Medicine, Faculty of Health Sciences, University of the Free State, Bloemfontein, South Africa
}

C Marais, ${ }^{1}$ 3rd-year medical student; J Smouse, ${ }^{1}$ 3rd-year medical student; G Poortier, ${ }^{1}$ 3rd-year medical student; A Fair, ${ }^{1}$ 3rd -year medical student;

Corresponding author: WJ Steinberg (SteinbergWJ@ufs.ac.za)

\begin{abstract}
Background. Modern people live increasingly longer lives owing to advances in medicine and medical technology. This has raised many ethical questions regarding the prolongation of life, the right to die and euthanasia.

Objective. To determine the opinions of medical students at the University of the Free State (UFS), South Africa (SA), regarding end-of-life practices: terminal pain management, withholding/withdrawing potentially life-sustaining treatment, advance directives and assisted dying. Methods. This was an observational, cross-sectional quantitative study. A self-administered and anonymous questionnaire was distributed to undergraduate medical students (preclinical and clinical). Demographic data were collected.

Results. The overall response rate was $71.6 \%$ (481/672; preclinical $82.4 \%$ and clinical $64.4 \%)$. Students agreed that patients should have access to medical care $(90.0 \%)$, and that pain medication should be state-supplied (86.3\%). Students agreed that patients should have the right to refuse medical care (72.1\%) and/or potentially life-preserving treatments (69.8\%). Overall, $67.3 \%$ of students agreed that doctors should have the right to turn off life support if requested in the patient's living will. Students (78.4\%) disagreed that life support may be turned off without consent. Clinical students (54.5\%) supported assisted dying being legal in SA, compared with the preclinical students (31.4\%). While $43.0 \%$ of students agreed that assisted dying should be legal, only $36.2 \%$ were willing to perform the procedure themselves. Conclusion. Medical students at UFS agree with the legislation of three of the end-of-life practices: terminal pain management, withholding/ withdrawing potentially life-sustaining treatment and advance directives. The clinical students, however, are more in favour than preclinical students of assisted dying becoming legal.
\end{abstract}

S Afr J Bioethics Law 2017;10(2):96-101. DOI:10.7196/SAJBL.2017.v10i2.604

Modern people live increasingly longer lives owing to advances in medicine and the application of medical technology, but this has raised many ethical questions regarding the prolongation of life, the right to die and euthanasia. ${ }^{[1,2]}$ In South Africa (SA), it is illegal to terminate a person's life or assist therein in order to end pain and suffering, even for a terminally ill patient. The common law criminalises euthanasia, but allows a patient to instruct a doctor to withhold/withdraw potentially life-sustaining treatment. ${ }^{[1]}$

According to the SA Law Commission, terminal illness refers to an illness, injury or other physical or mental condition that, in medical judgment, will inevitably cause the patient's death and is producing extreme suffering, or will cause an irreversible vegetative condition. ${ }^{[1]}$ In 2011, the Ethics Institute of SA (EthicsSA) ${ }^{[3]}$ conducted a scoping survey among doctors and specialists at two medical schools in SA, in which more than $80 \%$ of participating doctors indicated that assisted dying should only be contemplated when a patient is terminally ill, while $12 \%$ believed that assisted dying does not require a terminal illness.

End-of-life decisions are categorised into the following four practices by the legal fraternity: (i) terminal pain management; (ii) withholding or withdrawing of potentially life-sustaining treatment; (iii) advance directives; and (iv) assisted dying. Patients in SA have the right to affordable palliative care in the case of a terminal illness. ${ }^{[4]}$
Under the National Patients' Rights Charter, published by the Health Professions Council of SA (HPCSA), ${ }^{[4-6]}$ patients have the right to refuse treatment. The National Health Act No. 61 of $2003^{[6]}$ allows patients, in writing, to designate a person to act on their behalf when they are no longer capable of doing so themselves.

'Assisted dying' is an umbrella term that entails all end-of-life interventions in the dying process. ${ }^{[3]}$ 'Assisted suicide' means that a person intentionally provides the means for a competent person to take their own life. 'Voluntary active euthanasia' means that a competent person at the end of life asks another person to perform an act which is the proximate cause of death. In this article, the term 'assisted dying' will be used in a narrower sense to refer to both assisted suicide and voluntary active euthanasia.

While studies have concentrated on what qualified doctors think about end-of-life decisions, it is of interest to ascertain the opinions of medical students ('doctors in training'). A study was conducted among medical students at a university in Croatia about their opinion on euthanasia, before and after bioethics education on the topic. ${ }^{[7]}$ Before the course, their attitudes toward euthanasia largely varied with respect to religion and according to whether they were rural or urban. After the training, students were significantly more positive towards euthanasia, and no differences between subgroups were 
found. A study by Weber et al. ${ }^{[8]}$ among German final-year medical students revealed limited confidence and knowledge concerning palliative-care issues. A study in the Netherlands highlighted the need to pay more attention to education on end-of-life care in the medical curriculum. ${ }^{[9]}$

\section{Objective}

This study aimed to determine the opinions of medical students at the University of the Free State (UFS), Bloemfontein, SA, regarding end-of-life practices.

\section{Methods}

\section{Study design and population}

This was an observational, cross-sectional quantitative study, conducted between July and November 2016. The study population was all the registered first- to fifth-year medical students at the School of Medicine, UFS: 672 students in total.

The undergraduate MB ChB curriculum presented by UFS spans 5 academic years. During the second part of their studies, students gain clinical experience in teaching hospitals and clinics. For this study, firstand second-year students are referred to as the preclinical group. Thirdyear students had started with their first clinical semester at the time of the study, and are referred to, together with the fourth- and fifth-year students, as the clinical group. At the beginning of the third year, as part of an ethics module, students have four sessions on palliative care.

\section{Measurement}

The measurement tool, designed by the researchers, was a selfadministered and anonymous questionnaire adapted from the survey used by Landman, ${ }^{[3]}$ and was available in English only. Demographic data were collected. Students' opinions on the four end-of-life practices were determined by formulated questions or statements. Each question or statement had five options, of which participants had to mark one: strongly agree, agree, neutral, disagree and strongly disagree. Of the 12 questions, two questions focused on terminal pain management, withholding or withdrawing potentially life-sustaining treatment and advance directives. Six questions focused on the practice of assisted dying.

Questionnaires were handed out by the student researchers to the preclinical and third-year students during lectures, and collected after immediate completion. The clinical students completed their questionnaires in their respective rotation groups.

\section{Pilot study}

A pilot study was done on a convenient sample of 10 second-year occupational therapy students of the Faculty of Health Sciences, UFS, to enhance the validity of the questionnaire. Minor spelling changes were made to the questionnaire, and an additional question allowing the students to comment was added.

\section{Analysis of the data}

Data were analysed by the Department of Biostatistics, Faculty of Health Sciences, UFS. Categorical information was summarised by frequencies and percentages, and numerical variables by means, standard deviations or percentiles. For reporting of results, the categories 'strongly agree' and 'agree' were grouped together, as were the categories 'disagree' and 'strongly disagree'.

\section{Ethical considerations}

The protocol was approved by the Health Sciences Ethics Committee, UFS (ref. no. HSREC-S-45/2016). Permission was obtained from the Vice Rector: Research, Dean of the Faculty of Health Sciences and head of the School of Medicine, UFS. Participation was voluntary. Completing and handing in the questionnaire was considered to constitute consent to the study.

\section{Results}

The overall response rate was $71.6 \%(481 / 672)$. The response rate for each medical year group is indicated in Table 1. Almost all of the participants (96.8\%) were in the age range 17 - 25 years, and $41.3 \%$ were male and $58.7 \%$ female.

\section{Terminal pain management}

The majority of students (90.0\%) agreed that all people should be granted full medical care (Table 2). The fifth-year group had the lowest percentage agreeing (79.0\%), and the highest percentage disagreeing $(8.1 \%)$. Most students $(86.3 \%)$ agreed that patients should have access to state-supplied pain medication during endof-life care. The first-year group had the lowest percentage agreeing (77.0\%) and the highest percentage choosing the neutral option (17.6\%).

\section{Withholding potentially life-sustaining treatment} Most of the students (72.1\%) agreed that a patient should have the right to refuse medical care, while $69.8 \%$ agreed that patients should be allowed to refuse potentially life-preserving treatment (Table 3). A fifth (20.3\%) of the first-year students felt that patients should not have this right, compared with $9.7 \%$ of fifth-year students. First-year students were also the group with the highest percentage (26.4\%) disagreeing that patients should be allowed to refuse treatment.

\section{Advance directives}

Only $54.4 \%$ of first-year students agreed that they would turn off life support if this was requested in the patient's living will, compared with $79.0 \%$ of fifth-year students (Table 4). The majority of students (78.4\%) were of the opinion that a doctor should not be allowed to turn off life support without the consent of the family or the patient. More preclinical students were opposed to this practice than clinical students. However, at least $20 \%$ of fourth- and fifth-year students were neutral on this practice, compared with less than $10 \%$ each in the remaining groups.

\section{Assisted dying}

Across all five groups, only $36.2 \%$ would assist a patient in carrying out

Table 1. The response rates of undergraduate medical students in their respective year groups

\begin{tabular}{cll}
\hline & Students in year, $\boldsymbol{N}$ & Participants, $\boldsymbol{n}$ (\%) \\
\hline $\begin{array}{c}\text { Preclinical } \\
\text { 1st year }\end{array}$ & 178 & $148(83.1)$ \\
2nd year & 109 & $89(81.7)$ \\
Clinical & & \\
3rd year & 140 & $90(64.3)$ \\
4th year & 123 & $92(74.8)$ \\
5th year & 122 & $62(50.8)$
\end{tabular}


Table 2. The opinions of undergraduate medical students regarding pain management as an end-of-life practice (\%)

\begin{tabular}{|c|c|c|c|c|c|c|}
\hline & \multirow[b]{2}{*}{ All } & \multicolumn{2}{|c|}{ Preclinical } & \multicolumn{3}{|c|}{ Clinical } \\
\hline & & $\begin{array}{l}\text { 1st } \\
\text { year }\end{array}$ & $\begin{array}{l}\text { 2nd } \\
\text { year }\end{array}$ & $\begin{array}{l}\text { 3rd } \\
\text { year }\end{array}$ & $\begin{array}{l}\text { 4th } \\
\text { year }\end{array}$ & $\begin{array}{l}\text { 5th } \\
\text { year }\end{array}$ \\
\hline \multicolumn{7}{|c|}{ All people, irrespective of age or health status, should be granted full medical care } \\
\hline Strongly agree & 65.0 & \multirow{2}{*}{94.6} & \multirow{2}{*}{92.1} & \multirow{2}{*}{86.5} & \multirow{2}{*}{91.3} & \multirow{2}{*}{79.0} \\
\hline Agree & 25.0 & & & & & \\
\hline Neutral & 6.9 & 5.4 & 4.5 & 7.9 & 6.5 & 12.9 \\
\hline Disagree & 2.1 & \multirow{2}{*}{0} & \multirow{2}{*}{3.4} & \multirow{2}{*}{5.6} & \multirow{2}{*}{2.2} & \multirow{2}{*}{8.1} \\
\hline Strongly disagree & 1.0 & & & & & \\
\hline \multicolumn{7}{|c|}{ Patients should have state-supplied access to pain medication during end-of-life care } \\
\hline Strongly agree & 51.8 & \multirow{2}{*}{77.0} & \multirow{2}{*}{85.4} & \multirow{2}{*}{93.3} & \multirow{2}{*}{91.3} & \multirow{2}{*}{91.9} \\
\hline Agree & 34.5 & & & & & \\
\hline Neutral & 8.9 & 17.6 & 7.9 & 3.3 & 5.4 & 3.2 \\
\hline Disagree & 2.5 & \multirow{2}{*}{5.4} & \multirow{2}{*}{6.7} & \multirow{2}{*}{3.3} & \multirow{2}{*}{3.3} & \multirow{2}{*}{4.8} \\
\hline Strongly disagree & 2.3 & & & & & \\
\hline
\end{tabular}

Table 3. The opinions of undergraduate medical students regarding withholding potentially life-sustaining treatment as an endof-life practice (\%)

\begin{tabular}{|c|c|c|c|c|c|c|}
\hline & \multirow[b]{2}{*}{ All } & \multicolumn{2}{|c|}{ Preclinical } & \multicolumn{3}{|c|}{ Clinical } \\
\hline & & $\begin{array}{l}\text { 1st } \\
\text { year }\end{array}$ & $\begin{array}{l}\text { 2nd } \\
\text { year }\end{array}$ & $\begin{array}{l}\text { 3rd } \\
\text { year }\end{array}$ & $\begin{array}{l}\text { 4th } \\
\text { year }\end{array}$ & $\begin{array}{l}\text { 5th } \\
\text { year }\end{array}$ \\
\hline \multicolumn{7}{|c|}{ The patient should not have the right to deny medical care* } \\
\hline Strongly agree & 4.8 & \multirow{2}{*}{20.3} & \multirow{2}{*}{14.6} & \multirow{2}{*}{12.2} & \multirow{2}{*}{8.7} & \multirow{2}{*}{9.7} \\
\hline Agree & 9.4 & & & & & \\
\hline Neutral & 13.7 & 19.6 & 12.4 & 12.2 & 5.4 & 16.1 \\
\hline Disagree & 37.2 & \multirow{2}{*}{60.1} & \multirow{2}{*}{73.0} & \multirow{2}{*}{75.6} & \multirow{2}{*}{85.9} & \multirow{2}{*}{74.2} \\
\hline Strongly disagree & 34.9 & & & & & \\
\hline \multicolumn{7}{|c|}{ Patients should be allowed to deny potentially life-preserving treatment* } \\
\hline Strongly agree & 26.3 & \multirow{2}{*}{58.8} & \multirow{2}{*}{68.5} & \multirow{2}{*}{75.3} & \multirow{2}{*}{83.7} & \multirow{2}{*}{69.4} \\
\hline Agree & 43.5 & & & & & \\
\hline Neutral & 12.5 & 14.9 & 14.6 & 13.5 & 5.4 & 12.9 \\
\hline Disagree & 11.9 & \multirow{2}{*}{26.4} & \multirow{2}{*}{16.9} & \multirow{2}{*}{11.2} & \multirow{2}{*}{10.9} & \multirow{2}{*}{17.7} \\
\hline Strongly disagree & 5.8 & & & & & \\
\hline
\end{tabular}

Table 4. The opinions of undergraduate medical students regarding advance directives as an end-of-life practice (\%)

\begin{tabular}{|c|c|c|c|c|c|c|}
\hline & \multirow[b]{2}{*}{ All } & \multicolumn{2}{|c|}{ Preclinical } & \multicolumn{3}{|c|}{ Clinical } \\
\hline & & $\begin{array}{l}\text { 1st } \\
\text { year }\end{array}$ & $\begin{array}{l}\text { 2nd } \\
\text { year }\end{array}$ & $\begin{array}{l}\text { 3rd } \\
\text { year }\end{array}$ & $\begin{array}{l}\text { 4th } \\
\text { year }\end{array}$ & $\begin{array}{l}\text { 5th } \\
\text { year }\end{array}$ \\
\hline \multicolumn{7}{|c|}{ A doctor should have the right to turn off life support provided it is in the living will of the patient } \\
\hline Strongly agree & 24.0 & \multirow{2}{*}{54.4} & \multirow{2}{*}{65.2} & \multirow{2}{*}{78.9} & \multirow{2}{*}{70.7} & \multirow{2}{*}{79.0} \\
\hline Agree & 43.3 & & & & & \\
\hline Neutral & 16.9 & 17.7 & 15.7 & 13.3 & 22.8 & 12.9 \\
\hline Disagree & 8.5 & \multirow{2}{*}{27.9} & \multirow{2}{*}{19.1} & \multirow{2}{*}{7.8} & \multirow{2}{*}{6.5} & \multirow{2}{*}{8.1} \\
\hline Strongly disagree & 7.3 & & & & & \\
\hline
\end{tabular}

A doctor should have the right to turn off life support, with evidence of life not being sustainable, without the consent of family or the patient

$\begin{array}{lllllll}\text { Strongly agree } & 2.1 & 6.9 & 6.7 & 13.8 & 10.0 & 13.8 \\ \text { Agree } & 7.5 & & & & \\ \text { Neutral } & 12.0 & 8.3 & 6.7 & 9.2 & 18.9 & 22.4 \\ \text { Disagree } & 32.5 & & & & & \\ \text { Strongly disagree } & 45.9 & 84.7 & 86.5 & 77.0 & 71.1 & 63.8\end{array}$

a procedure linked to assisted dying, while $45.3 \%$ would not assist and $18.5 \%$ were neutral (Table 5). Half (53.8\%) of the preclinical students would not assist a patient in carrying out a procedure linked to assisted dying. The clinical group was slightly more in favour of the idea, with at least $40 \%$ willing to carry out the procedure. A higher percentage of this group, however, remained neutral compared with the preclinical group.

Clinical students were more inclined to opt for assisted dying if they were ever terminally ill themselves $(54.9 \%)$, while only $31.0 \%$ 
Table 5. The opinions of undergraduate medical students regarding assisted dying as an end-of-life practice (\%)

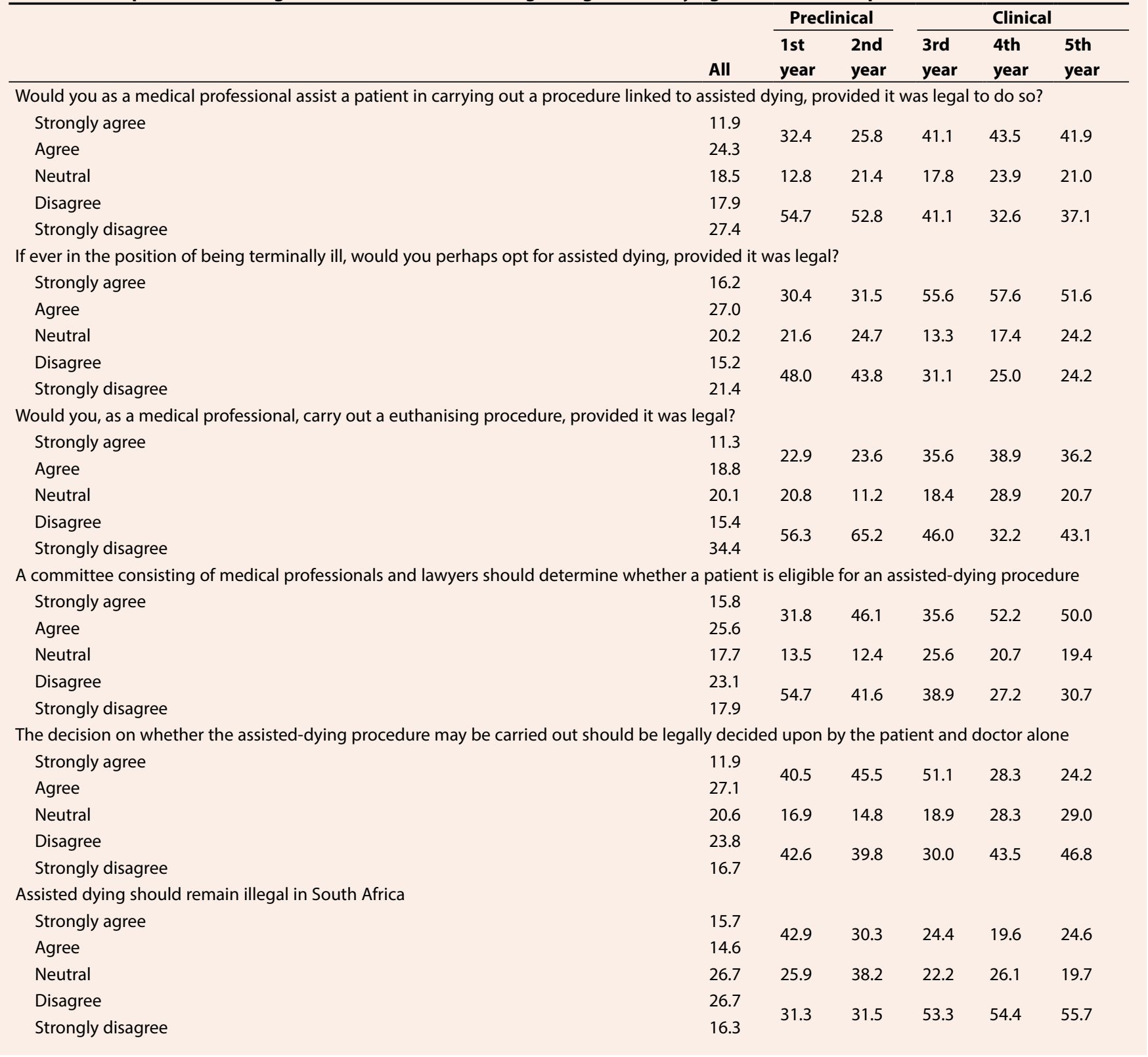

of preclinical students agreed, and $23.2 \%$ remained neutral. In the clinical group, the percentage of students remaining neutral increased from $13.3 \%$ in the third years to $24.2 \%$ in the fifth years.

Except for the fourth-year students, the highest percentage in each group would not carry out a euthanising procedure, even if it was legal. Just over $60 \%$ of preclinical students would not carry out this procedure, compared with $44.6 \%$ of third- and fifth-year students. Overall, secondyear students had the highest percentage of disagree responses (65.2\%). Even though the highest percentage of fourth-year students (38.9\%) agreed that they would carry out a euthanising procedure, they were also the group with the highest percentage of neutral responses (28.9\%).

Medical students were almost equally divided between agreeing $(41.4 \%)$ and disagreeing (41.0\%) that a committee consisting of medical professionals and lawyers should determine whether a patient is eligible for an assisted-dying procedure. First-year students mostly disagreed (54.7\%), while half of fourth- and fifth-year students agreed. There was no definite trend between the preclinical and clinical groups; second, fourth and fifth years were more inclined to agree, while first and third-years tended to disagree.

The students were also almost equally divided (39.0\% agree; $40.5 \%$ disagree) on whether or not the decision to carry out an assisted dying procedure should be legally regulated upon by the patient and doctor alone. No definite trend was apparent. The highest percentage in secondand third-years agreed, while first, fourth and fifth years disagreed.

While $43.0 \%$ of students disagreed that the practice of assisted dying should remain illegal in SA, more than a quarter (26.7\%) were neutral. First-year students tended to agree with this statement $(42.9 \%)$, whereas more than $50 \%$ of clinical students disagreed.

\section{Discussion}

Results from this study show that undergraduate medical students at UFS agree that terminally-ill patients should receive terminal pain management and have access to pain medication during end-of-life care. This is in line with the HPCSA's National Patients' Rights Charter. ${ }^{[4]}$ 
There was a strong leniency towards the patient having the right to refuse medical care and potentially life-preserving treatment, which is in line with current legislation..$^{[1]}$ The clinical group was more in agreement with this practice than the preclinical group, showing that students in their clinical years are more accommodating of patient autonomy.

The clinical students clearly supported the practice of allowing patients to make decisions regarding their life and health. Most of the students would turn off life support if this was specified in a living will; however, a percentage of students indicated that they would not turn off life support even when consent was given in a living will. The majority of students were clear on the issue that life support should not be turned off unless prior permission or discussion had occurred with the family or patient. In the EthicsSA survey, $75 \%$ of responding doctors agreed that advance directives help to clarify a patient's wishes regarding treatment when incompetent and at the end of life, whereas only $12 \%$ disagreed. ${ }^{[3]}$

Differing opinions were seen between the preclinical and clinical groups regarding the practice of assisted dying. The role of clinical exposure and responsibility affecting the view of assisted dying needs to be further investigated.

The question on whether students would opt for assisted dying should they themselves be terminally ill showed that it seems a more realistic possibility for the clinical students, after exposure to termina cases. There was a $20.0 \%$ difference between the preclinical and clinical groups for this scenario, with clinical students more in favour of opting for assisted dying if they were the patient. When the question was directed at their professional opinion as to whether they are willing to carry out an assisted dying procedure, the difference dropped to under $10 \%$. This may be the result of clinical students realising that their professional and personal opinions overlap. They need to accept that, if they would ever want the procedure carried out on themselves, they may be obliged to perform an assisted dying procedure. A slightly higher percentage of medical students $(30.1 \%)$ would be willing to carry out a euthanising procedure than the $25 \%$ of respondents in the EthicsSA study, ${ }_{1}^{[3]}$ affirming that they would administer a lethal drug, if requested, provided euthanasia was legal. Our results also showed that $36.2 \%$ of the students would help a patient to carry out an assisteddying procedure, compared with $30.1 \%$ who would carry out voluntary active euthanasia. Although the difference is only $6.1 \%$, the results may indicate that medical students make a moral distinction between assisted dying and euthanasia.

First-year students showed more support for the doctor and patient to make an end-of-life decision rather than a multiprofessional committee consisting of medical professionals and lawyers. However, the more experienced clinical students (fourth and fifth years) showed more support for allowing a committee to make the decision rather than the doctor and patient alone. These two year-groups also had the highest neutral percentages of $28.3 \%$ and $29.0 \%$, respectively, on whether they think the doctor and patient should have sole responsibility in end-of-life decisions. The clinical students therefore seem to better appreciate the support of the multi-professional committee, or to want to delegate the responsibility to someone else.

Current laws in SA do not allow either assisted dying or the carrying out of euthanising procedures. In 2016, SA's laws were challenged on this matter by the Stransham-Ford $v$ the State case, where the
Supreme Court of Appeals denied the prosecutor the right to have the procedure carried out on Robert Stransham-Ford, overturning the ruling of SA's High Court made in 2015..$^{[10]}$ The question as to whether assisted dying should remain illegal in SA is central to this study. Overall, $43.0 \%$ of students felt that assisted dying should be legalised, while $26.7 \%$ remained neutral. However, just over $30 \%$ of preclinical students supported legalising assisted dying, compared with more than $50 \%$ of clinical students. According to the EthicsSA survey, $38 \%$ of physicians indicated that doctor-assisted suicide should be legalised. When further asked if voluntary active euthanasia should be legalised, $34 \%$ strongly agreed or agreed. ${ }^{[3]}$

Even though $43.0 \%$ of the students agreed that assisted dying should be legalised in SA, only $36.2 \%$ would be willing to be involved. This result shows that clinical students at UFS have similar views to practising doctors in Bloemfontein on this issue. ${ }^{[3]} \mathrm{A}$ similar study on attitudes towards euthanasia and physician-assisted suicide in Switzerland showed significant variations among medical students, oncology clinicians and palliative-care specialists. ${ }^{[1]]}$ It does seem that, in general, fewer doctors than students are in favour of assisted dying. However, another study in 2009 that aimed to find out the opinions of doctors in the private sector in Bloemfontein indicated that $82.3 \%$ of the doctors would never perform an assisted-dying procedure. ${ }^{[12]}$ It is not clear whether this may indicate a change in views over time, or a lack of standardised measuring tools used by the different studies.

\section{Study limitations}

During the study, fifth-year students were busy with their final examinations. The poor response rate among the fifth-year students may have resulted in biased results.

The measuring tool was adapted to create scenarios more understandable to medical students, rather than medical practitioners.

Students were not given much time to deliberate and prepare, nor to discuss answers to the questions. Furthermore, this study only reports on the opinion of the current medical students of one medical institution in the country.

\section{Conclusion and recommendations}

From the results, medical students at UFS agree with the legislation of three of the end-of-life practices: terminal pain management, withholding or withdrawing potentially life-sustaining treatment and advance directives. The clinical students, however, are more in favour than the preclinical of assisted dying becoming legal.

The topic of assisted dying should be integrated into the curriculum, making available adequate background information and implications for practice, so that a well-informed decision can be made. The authors recommend further studies to obtain opinions from other medical schools in SA.

Acknowledgements. The authors thank $\operatorname{Dr} \mathrm{L}$ van der Merwe, Undergraduate Medical Programme Director, School of Medicine, UFS, for her assistance with the logistical arrangements, and Ms T Mulder, medical editor, School of Medicine, UFS, for technical and editorial preparation of the manuscript. The students' voluntary participation in the study is appreciated.

Author contributions. CM, JS, GP and AF developed the protocol, performed the data collection and did the initial write-up of this 
study. GJ assisted with the planning, performed the data analysis and assisted with the interpretation and write-up of this study. WJS was the supervisor of this study, suggested the concept, assisted with the protocol development, data collection and interpretation of data, and was responsible for the write-up of this study.

Funding. None.

Conflicts of interest. The authors declare that they have no financial or personal relationships that may have inappropriately influenced them in the writing of this article.

1. South African Law Commission. Euthanasia and the Artificial Preservation of Life. Project 86. Pretoria: SA Law Commission, 1998.

2. Chidoori REP. Should passive euthanasia be made legal in South Africa? Doctoral dissertation. East London: University of Fort Hare, 2009.

3. Landman WA. End-of-life decisions, ethics and the law: A case for statutory legal clarity and reform in South Africa. Geneva: Globethics.net, 2012. http:// www.globethics.net/documents/4289936/13403252/FocusSeries_09_ EndOfLifeDecision Willem text.pdf/e4c50a25-5c89-465b-b341-e7a957d5a1da (accessed 7 December 2015).

4. Health Professions Council of South Africa. National Patients' Rights Charter. Booklet 3. Pretoria: HPCSA, 2008.

5. Health Professions Council of South Africa. Guidelines for the Withholding and Withdrawing of treatment. Booklet 12. Pretoria: HPCSA, 2008.
6. South Africa. National Health Act No. 61 of 2003

7. Sorta-Bilajac I, Brkanac D, Brozović B, et al. Influence of the 'Rijeka model' of bioethics education on attitudes of medical students towards death and dying - a cross-sectional study. Coll Antropol 2007;31(4):1151-1157.

8. Weber M, Schmiedel S, Nauck F, Alt-Epping B. Knowledge and attitude of finalyear medical students in Germany towards palliative care - an interinstitutional questionnaire-based study. BMC Palliat Care 2011;10(19):1-7. https://doi. org/10.1186/1472-684X-10-19

9. Hesselink BA, Pasman HR, van der Wal G, Soethout MB, Onwuteaka-Philipsen $B D$. Education on end-of-life care in the medical curriculum: Students' opinions and knowledge. J Palliat Med 2010;13(4):381-387. https://doi.org/10.1089/ jpm.2009.0291

10. Stransham-Ford $v$ the Minister of Justice and Correctional Services and Others 2015 (4) SA 50 (GP). http://www.saflii.org/za/cases/ZASCA/2016/197.pdf (accessed 10 May 2017).

11. Marini MC, Neuenschwander $\mathrm{H}$, Stiefel F. Attitudes toward euthanasia and physician assisted suicide: A survey among medical students, oncology clinicians, and palliative care specialists. Palliat Support Care 2006;4(3):251-255. https://doi. org/10.1017/S1478951506060329

12. Brits L, Human L, Pieterse L, Sonnekus P, Joubert G. Opinions of private medical practitioners in Bloemfontein, South Africa, regarding euthanasia of terminally ill patients. J Med Ethics 2009;35(3):180-182. https://doi.org/10.1136/ jme.2008.027417

Accepted 17 October 2017. 